\title{
Teaching in the COVID-19 Era: Personal Reflections, Student Surveys and Pre-COVID Comparative Data
}

\author{
Tariq Khraishi \\ Mechanical Engineering Department, University of New Mexico, Albuquerque, New Mexico, USA \\ Email:khraishi@unm.edu
}

How to cite this paper: Khraishi, T. (2021). Teaching in the COVID-19 Era: Personal Reflections, Student Surveys and Pre-COVID Comparative Data. Open Journal of Social Sciences, 9, 39-53.

https://doi.org/10.4236/jss.2021.92003

Received: January 2, 2021

Accepted: February 4, 2021

Published: February 7, 2021

Copyright $\odot 2021$ by author(s) and Scientific Research Publishing Inc. This work is licensed under the Creative Commons Attribution International License (CC BY 4.0).

http://creativecommons.org/licenses/by/4.0/

\section{(c) (i) Open Access}

\begin{abstract}
Online teaching has emerged powerfully worldwide due to the COVID-19 pandemic. This paper recounts the personal experience of the author teaching his first full-time virtual course online in a synchronous fashion. The author provides back reflection on his Fall 2020 course enumerating advantages and disadvantages for virtual teaching versus in-person teaching. The author also gathered student feedback in the form of a survey on their first fully-immersed COVID experience as a full online live course. Data comparing the pre-COVID course grades and course evaluations to the COVID outcomes are also provided. Based on the survey and grades/course evaluations comparisons, it is concluded that the shift to pure online teaching was successful.
\end{abstract}

\section{Keywords}

Virtual Teaching, Online Learning, COVID-19 Pandemic, In-Person Teaching, Teaching Modality

\section{Introduction}

The move to deliver courses online is not a new thing. Indeed, for the past tens of years, this is a modality that has been developed and still continues to see development in terms of features and capabilities. The earliest attempt at online learning was in 1982 (Wikipedia, 2020). With the advent of the Internet, the easy and mostly free arrival of information took hold. However, since then people started thinking about the use of the Internet in more structured formats or ways instead of the complex information delivery/gathering inherent with the world-wide "web" concept. People started focusing on how to move traditional teaching from in-person to a virtual or online (Wikipedia, 2020). 
With that thinking or focusing, the questions of efficiency or even equivalency between in-person and online teaching modalities have emerged. Scholars or researchers engaged into contrasting plusses or minuses (advantages or disadvantages) of the two teaching modalities. According to Drexel University (Drexel University School of Education, 2020), there are four benefits for online education: "There are many advantages to virtual learning that can help you sharpen your skills and grow in your career. Courses taught online provide students the flexibility to learn on their own schedule, instead of a mandatory class time. Online courses, including those taught at Drexel cost less than traditional on-campus courses, making them more affordable. Virtual courses give students more selection in their courses. In a face-to-face setting, courses taught at the same time force students to choose between courses they like. Lastly, virtual learning gives students access to classmates all around the world, providing networking opportunities you can't get through an on-campus program."

As for online teaching, it divides into two main categories: Synchronous and Asynchronous (Finol, 2020). The difference is that the former provides real-time teaching of students in a course, whereas the latter lacks the real-time nature of delivery. By this definition, even "in-person classes" are defined as "Synchronous." Of course, "Synchronous" teaching could be done in a variety of ways. For example, it could involve only writing, e.g. chatting, texting, emailing, etc., or could also involve audio and/or video of the course participants (teachers and students). As for the "Asynchronous" teaching, this could also entail all of the above elements, just not in real-time. The word "Virtual" teaching implies audio and video. Virtual teaching could be either Synchronous or Asynchronous. For the author personally, the word "Virtual" implies Synchronous delivery. However, searching through literature, there was not a unified definition of "Virtual" teaching. For example, according to Arlington Public Schools (2020), "Synchronous learning is interactive, two-way online or distance education that happens in real time with a teacher, whereas asynchronous learning occurs virtually online and through prepared resources, without real-time teacher-led interaction." This reference indicates that "Virtual" is by default an "Asynchronous" modality. Another reference (IGI Global, 2020) agrees with the last definition saying that Virtual Education is "Another name for e-learning, but referring more to electronically aided learning conducted without any face-to-face components."

However, according to Beek (2011), "Specifically, virtual learning uses computer software, the Internet or both to deliver instruction to students. This minimizes or eliminates the need for teachers and students to share a classroom." Also, LearnCube (2017) defines it as "A virtual classroom is an online learning environment that allows teachers and students to communicate, interact, collaborate and explain ideas." According to the last two references, Virtual is not pegged to Asynchronous.

The year 2020 has been a different year than most living people have witnessed. The world-wide COVID-19 pandemic that gripped the world has neces- 
sitated a lot of changes in human behavior in many developed countries. These changes revolved around reducing human contact or face-to-face interaction in an effort to stymie the spread of this air-borne or respiratory disease. That is why rules such as "social distancing" were broadcasted in communities. With such rules, as well as other rules on mask use which can muffle speech/sound, in addition to other rules about hand-sanitizing especially after touching items touched by others, the prospect of holding in-person teaching has considerably diminished. Due to all of the above, a majority of universities across the USA have moved to purely online teaching. According to Quintana (2020), "earlier this year, nearly two-thirds of institutions had planned on in-person instruction" for the Fall 2020 semester or trimester. However, as the Fall came and the pandemic stats was only getting worse, most colleges switched to online teaching. Indeed, according to The Chronicle of Higher Education (2020), the percentage of four-year public institutions providing primarily in-person education was only $20 \%$. For two-year public institutions, this percentage dipped further to about $16 \%$. It is within this context, or global COVID-19 background, that this study emerged.

Here we offer some background for this paper. The author works in the School of Engineering at the University of New Mexico (USA), a four-year public institution that is classified as Minority Institution (MI) and a Hispanic-Serving Institution (HSI). The author was slated to teach a graduate course (ME512 Introduction to Continuum Mechanics) in Fall 2020 as a hybrid course (about half the students in-person with the teacher, and about half remote or live online). However, one week before the semester started, the University switched all students to pure online modality. Such sudden switch has caused the teacher, and perhaps some students, unrest or at least uncertainty since it was not planned by them. More importantly, the teacher had to quickly switch his course offering and its materials to suit an online modality whereas his colleagues had since the Spring 2020 semester to adapt to such shift for their online offerings. Having given it a quick and intense thought process, the author determined that he will meet synchronously with all the students live online via Zoom (since the University had a license for it). However, since no digital material was prepared for the course during the summer, the author requested a document camera to enable hand-written notes or explanation of materials to the students. The University supplied the teacher with a document camera (HoverCam Solo 8 Plus Document Camera) shown in Figure 1. With this USB-powered device, the author was ready to start his first-ever fully live or synchronous teaching experience for a whole semester. The rest is just history and I herein share my personal experiences with interested others via this paper.

It is worth mention that there are other teachers who published papers regarding comparison between courses offered under two different modalities: in-person and online. LaMeres and Plumb (2014) found out that converting undergraduate digital circuits to online delivery is as effective as in-classroom offerings. They even found the same result for an undergraduate digital system 


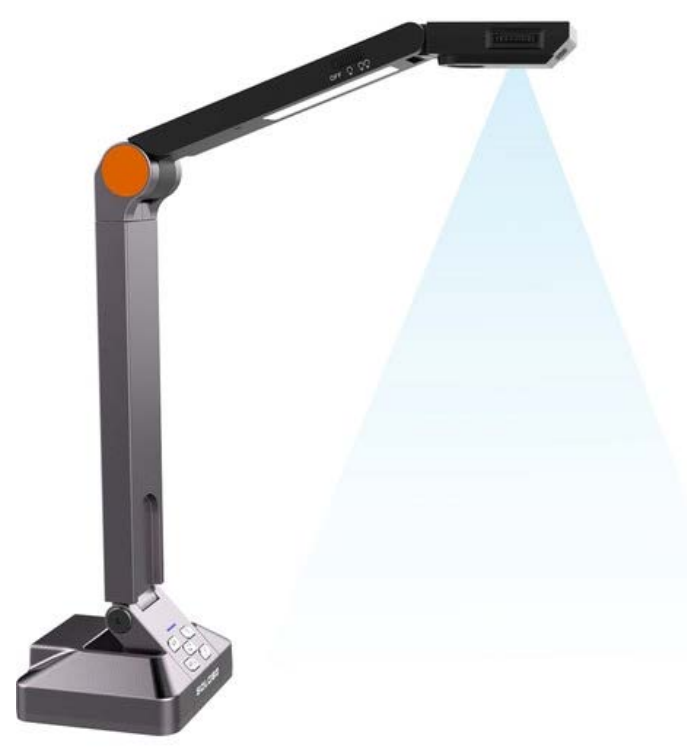

Figure 1. Document camera used by the author in his course.

laboratory using a remote lab approach. Reid (2006) in the Electrical and Computer Engineering Technology Department at IUPUI studied the conversion of two courses (Digital Fundamentals and $\mathrm{C}++$ programming) has gradually changed two courses from a traditional lecture/laboratory format to an online format. They found that student success was comparable to success in a traditional format using a self-assessment and final exam scores. But they found serious issues with student retention and with student satisfaction with the online format of course offering. Pisupati \& Mathews (2008) found out that "the average quiz scores for online and face-to-face sections were identical". They also found out similar average scores for the midterm and final exams. However, they found out that the students perceived the online portion/format to be more difficult and challenging. Douglas (2015) found out for an engineering statics course that "there was little to no difference in content mastery between students who completed the online and face-to-face sections of the class". This includes score on identical proctored exam problems. However, they also found that the withdrawal and non-completion rates were higher in the online classes than the face-to-face classes. The most recent reference on this is by Khraishi \& Denman (2019). In this paper, it was found out that the online class resulted in general in lowered letter grades and course component attainment. Overall though, it appears the transition to an online course had no bearing on the two main components of the course (the midterm and final exams). The components that got affected were those involving group works, specifically homeworks and group presentation. It appears that the lack of in-person meeting for group members affected the communication and grouping needed to better accomplish the group tasks. The inclusion of quizzes in the online classes also contributed to lowered overall class scores due to the discipline required to be successful in these quizzes. 
There has been a flurry of new publications dealing with the emergency created by COVID-19 on teaching \& learning worldwide. For example, George (2020) reported general student satisfaction with the shift to online teaching as well as final exam scores comparable to previous years. This was for an introductory digital electronics course. Dost et al. (2020) have surveyed thousands of UK medical students about the change to online education during the COVID-19 pandemic. It was found that "the greatest perceived benefits of online teaching platforms included their flexibility. Whereas the commonly perceived barriers to using online teaching platforms included family distraction (26.76\%) and poor internet connection (21.53\%)." Co \& Chu (2020) had to develop online teaching for basic surgical skills training. They found that "When compared to face-to-face teaching. Most students $(\mathrm{N}=22,73.4 \%)$ felt that the web-based surgical skills learning (WSSL) was just as difficult/easy as conventional teaching for learning instrumental knots." Lee (2020) showed that, for online teaching of chemistry during COVID-19, "the average satisfaction score (25) for synchronous online lectures was 2.86, while that for asynchronous lectures was 3.40, showing that overall the students preferred asynchronous lectures to real-time lectures, possibly due to the flexibility of asynchronous lectures." Guo (2020) found that "students who did not attend the synchronous sessions found the course more difficult and felt they spent more time on the class than those who attended", and that "students who attended the synchronous sessions saw an average test grade drop of 3.5\%, students who did not attend saw a drop of 14.5\%". The paper by Gelles et al. (2020) have indicated that faculty members communication of care and incorporation of flexibility in their courses, was a key element for supporting students' well-being and success. Ripoll et al. (2021) replaced a traditional mid-term exam in a Biochemical Engineering course with a sequence of collaborative and active learning activities. They found that the adopted methodology had a positive impact of student performance.

The goal of this work is to evaluate the sudden switch to online teaching and its impact on course offering. This paper is different than the previous COVID-related papers in the following senses. First, this appears to be the first one dealing with the effect of COVID on Fall 2020 courses. Prior references dealt with a partial switch to online in Spring 2020 and not a full switch like this paper deals with. Second, this paper compares grades and course evaluations from prior years to the COVID-transformed course. This provides important data on student and faculty performance.

\section{Methods}

The method employed for this paper, was fully-online and synchronous teaching modality for a graduate course with a moderate class size $(<20)$. The course was taught live via Zoom, lectures were recorded every time, and a document camera was utilized every lecture to write in real-time notes or material explanation by the teacher's hand. This experience generated certain reflections and response 
within the author as pertaining to full online teaching. A survey was done at the end of the semester to probe how the students felt about the course. Also, the regular course evaluation requested by the University was collected and compared to pre-COVID evaluations for the same course. Lastly, grades from the Fall 2020 were compared to pre-COVID grades for the same course.

\section{Results and Discussion}

\subsection{Personal Reflection on Virtual Teaching}

The experience that the author gained by this sudden full-immersion in a fully-online synchronous course offering for the first time in his career, has sparked many thoughts in his mind and a comparison of plusses/advantages and minuses/disadvantages of such modality versus typical in-person course offering. Below, are my personal thoughts on this teaching experience:

1) Using Zoom sessions, I can see all the student faces up close (there was a requirement for all students to show themselves during class), unlike a lecture hall/room with my back to them as I write on the board. This way I can catch who is dozing off and then ask them questions to engage them in the class material. Also, the students are less likely to doze off since they all being watched by the whole class (small class number of about 18) unlike typical seating pattern in a classroom. I actually felt a pretty good control over the happenings of the lecture or class time much more so than I felt with in-person teaching.

2) I utilize a textbook for this course. Teaching with Zoom has allowed me less intense class preparation since I can peek back quickly into my textbook and not have to remember all my class prep. That reduces class prep time and also makes me look better prepared.

3) I was able to not just write text under a document camera just like I would do on a white board for in-person class lecturing (without the messiness of chalk or dry erase markers), but also I did not have to re-draw pictures from my textbook and could just slide the textbook under the doc camera to show the pictures. This saved a lot of time that I used to spend in the past for in-person classes, since I did not have to re-create the wheel so-to-speak anymore, and this time was diverted to more in-depth discussion of textbook material. This is so since I am not in as much rush anymore and hence that should benefit the educational goals of better delivery or explanation of material during the lecture.

4) The availability of the document camera allowed me to go back and forth on different pages of the textbook and continuously remind the students of previous information covered in class.

5) Save my legs! I do not have to be standing for an hour or more and thus it was more relaxing and more comforting sitting in my high-back chair in the comfort of my own office (or home office for some).

6) Even without raising my voice, like I used to do for in-person lecturing say when I was sick or down that day or lecturing in a big room/hall, I can instead turn up the volume on my computer or the students can do the same and then 
all can hear the audio well.

7) There is further time saving as I do not have to walk back and forth to the lecture room/hall, or drive there for some. Again, this time savings allowed me more in-depth discussion of class material that I never felt I had the time for before pre-COVID.

8) I was worried about how the tests/exams would go (knowing that I do open book exams). However, I was able to share the exam questions with them via Zoom. They would then write their answers on blank pages they have. After they are done with the exam, they would either scan or take pictures of the pages and then email them to me. My initial concerns of any dishonesty appeared unfounded as I did not see any indication of that.

9) Another benefit for taking the exams live via Zoom was that whenever any student asked a question, all other students heard it and heard the teacher response. This was not always the case for in-person teaching of the same course.

10) I practice in this course a version of the "one-minute problem" or two-minute problem. I ask the students to pre-read the textbook chapter or parts of it, and then in class I ask them to solve some relatively quick problems based on material we just covered. Pre-COVID they used to do so in groups of two but using Zoom they were asked to work on them individually. Although collaborative work on such problem is definitely a plus, there is value in individualized attention to each problem. Furthermore, once some students solved the problem, they are asked to share their solution with others. Zoom allows easier oral communication with everyone else logged in. However, it is hard for students to share in writing the details of their solution since they do not have a document camera like the teacher nor can they write things on a white board for all to see.

11) The other clear benefit to me is that I can easily pull different online or computer resources to share with the students (at the click of a mouse like it is said). In a pure in-person modality that is not doable unless you are in a special classroom with TVs or screens to share info with the students or you rely on their personal laptops/cell phones to pull certain info.

Having shared above all my personal thoughts on my virtual online teaching experience, it is important to resort to other non-personal data to shed light on other important aspects of this particular course teaching. These are things like: a) students' feelings about this virtual course experience, b) comparison of course evaluations with pre-COVID evaluations, and c) comparison of course grades with pre-COVID course grades.

\subsection{Student Survey Results}

Let's turn our attention to a student survey trying to probe the students' feeling about this switched course modality from hybrid to pure online, as well as try to measure students' feelings about the COVID atmosphere surrounding all of us. In Figures 2-9, are eight different survey questions and the response of students to them. 
Is this your first fully-online course? Part online like what happened end of Spring 2020 does not count here as "fully-online"

Answered: 16 Skipped: 0

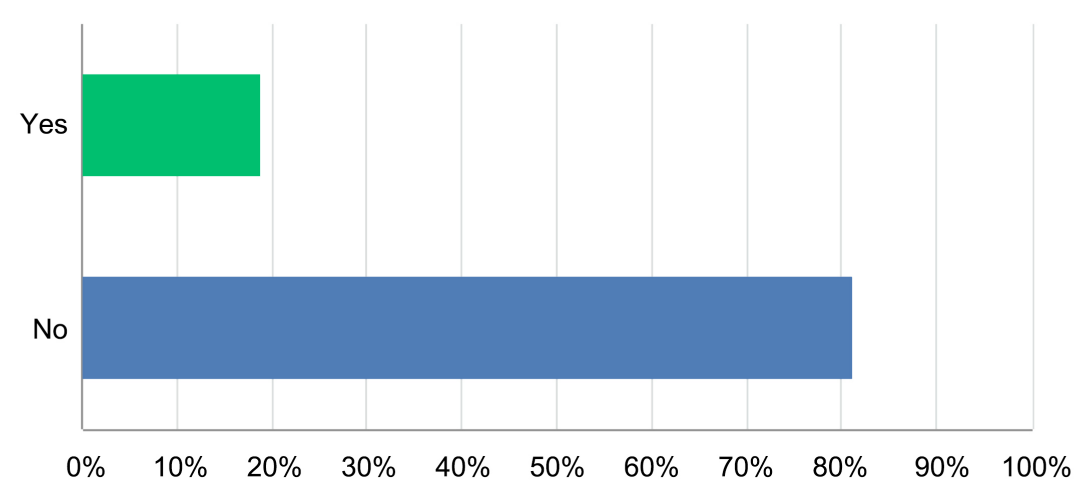

ANSWER CHOICES

$$
\text { - Yes }
$$

- No

TOTAL
- RESPONSES

$18.75 \%$

$81.25 \%$ 16

Figure 2. Question 1 of the student survey.

When the University switched this course to a fully-online format right before the start of the Fall 2020 semester, what was your feeling then about such switch?

Answered: $16 \quad$ Skipped: 0

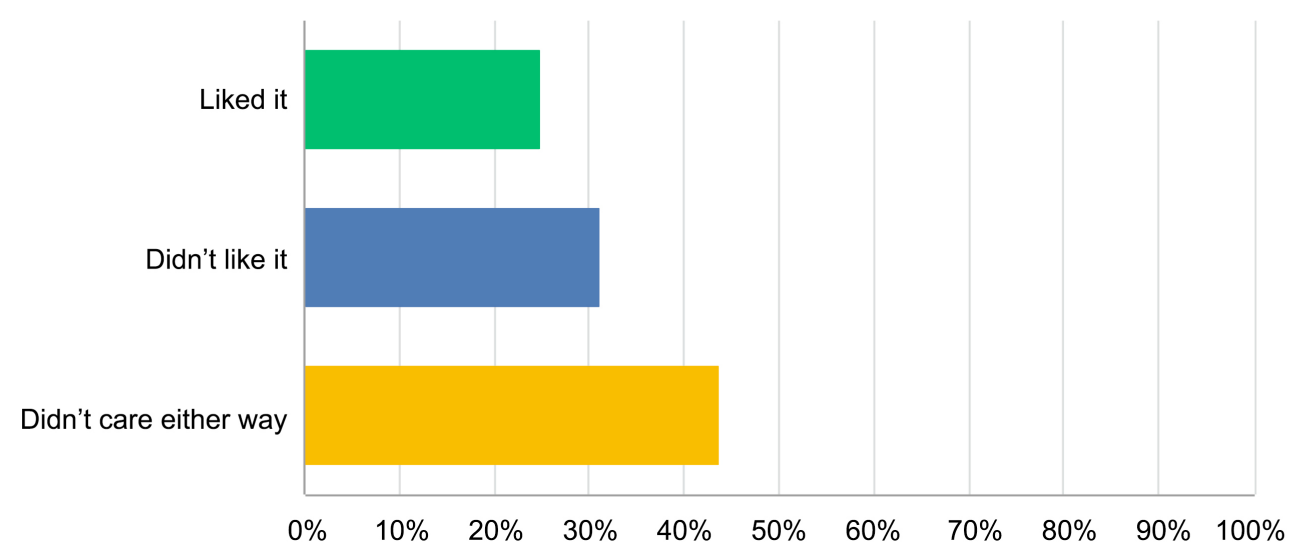

\section{ANSWER CHOICES}

- Liked it

$\checkmark$ Didn't like it

- Didn't care either way TOTAL
- RESPONSES

$25.00 \%$

$31.25 \%$

$43.75 \%$ 7 16

Figure 3. Question 2 of the student survey. 
If this is your first fully-online course, how did you feel about this virtual/online experience with taking this course?

Answered: 16 Skipped: 0

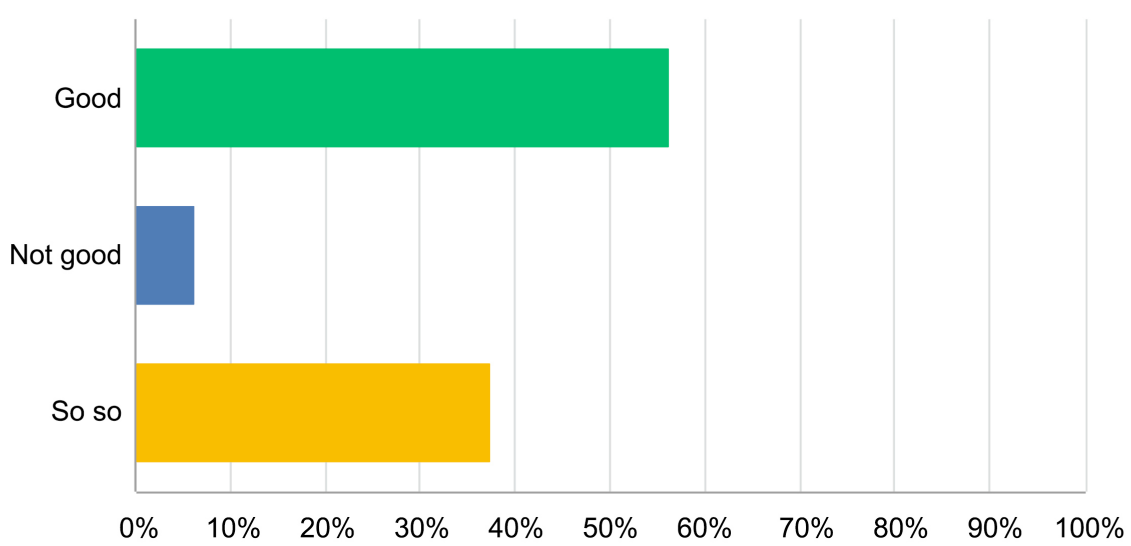

ANSWER CHOICES

- Good

- Not good

- So so

TOTAL
- RESPONSES

$56.25 \%$

$6.25 \%$

$37.50 \%$

6

16

Figure 4. Question 3 of the student survey.

Based on your experience with this course, do you think that the virtual/online format has any advantages (or plusses) over the in-person class format?

Answered: 16 Skipped: 0

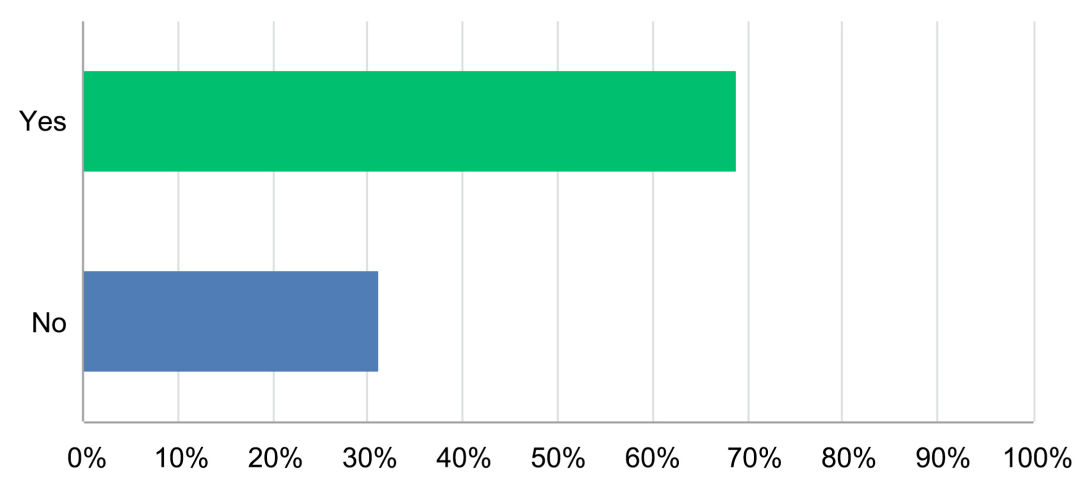

ANSWER CHOICES

- Yes

$\checkmark$ No

TOTAL
- RESPONSES

$68.75 \%$

$31.25 \%$ 5

16

Figure 5. Question 4 of the student survey. 
Based on your experience with this course, do you think that the advantages (or plusses) for virtual/online courses are more than the advantages/plusses for in-person class courses?

Answered: 16 Skipped: 0

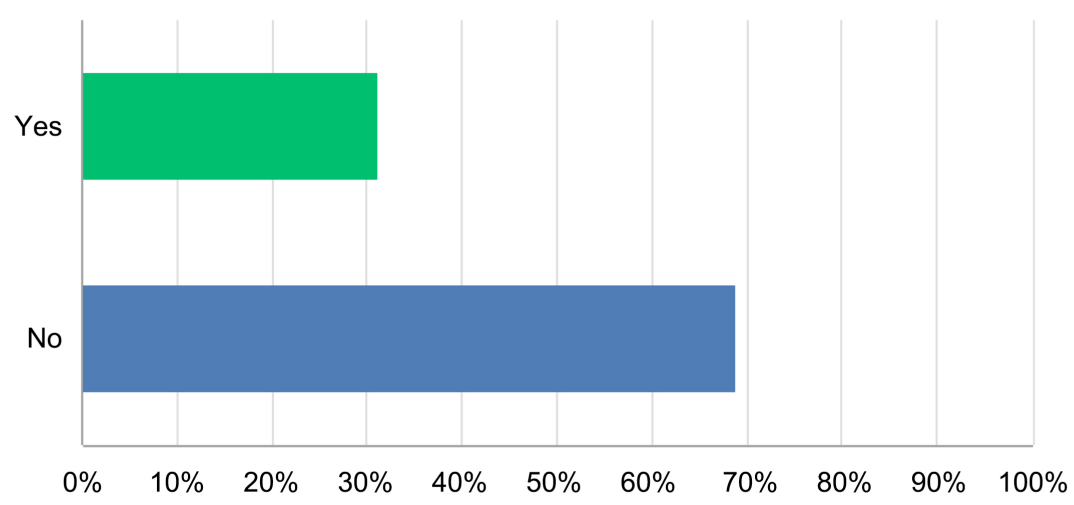

ANSWER CHOICES

$\checkmark$ Yes

- No

TOTAL
- RESPONSES

$31.25 \%$

$68.75 \%$

Figure 6. Question 5 of the student survey.

Based on your experience with this course, do you think that you would consider (if you have the choice) taking more virtual/online courses in the future even if the COVID situation is resolved?

Answered: 16 Skipped: 0

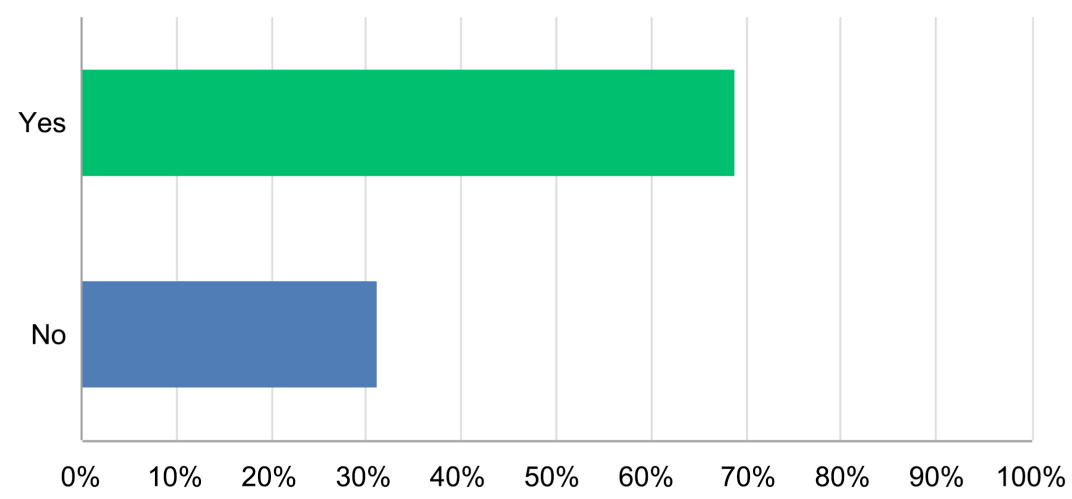

ANSWER CHOICES

$\checkmark$ Yes

- No

TOTAL
- RESPONSES

$68.75 \%$

$31.25 \%$

5

16

Figure 7. Question 6 of the student survey. 
Given the COVID situation, do you think that the University did the right thing in moving this course to a fully virtual/online format from the in-person format?

Answered: 16 Skipped: 0

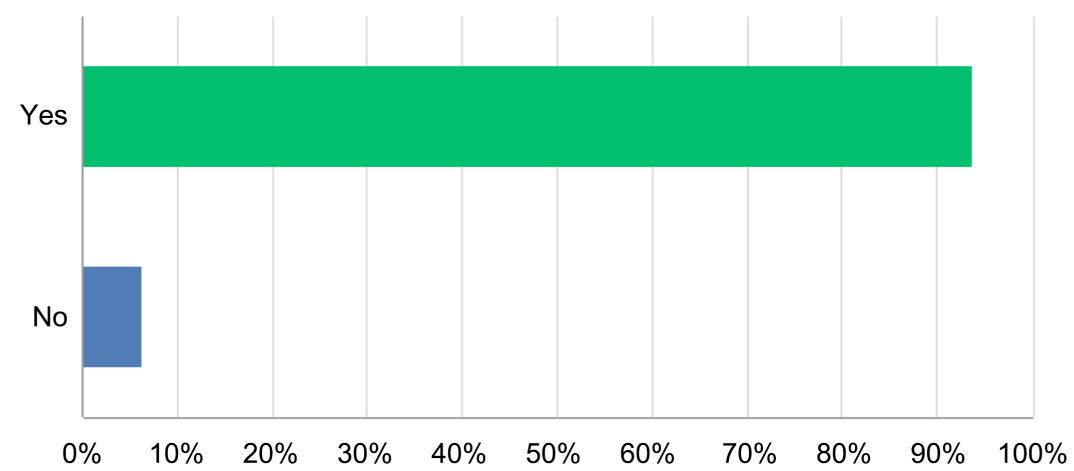

ANSWER CHOICES

$\checkmark$ Yes

- No

TOTAL
- RESPONSES

$93.75 \%$

$6.25 \%$

1

16

Figure 8. Question 7 of the student survey.

Do you prefer the use of a live document camera for explaining course material (as in this course) OR pre-prepared PowerPoint slides with the class material already on such slides?

Answered: 16 Skipped: 0

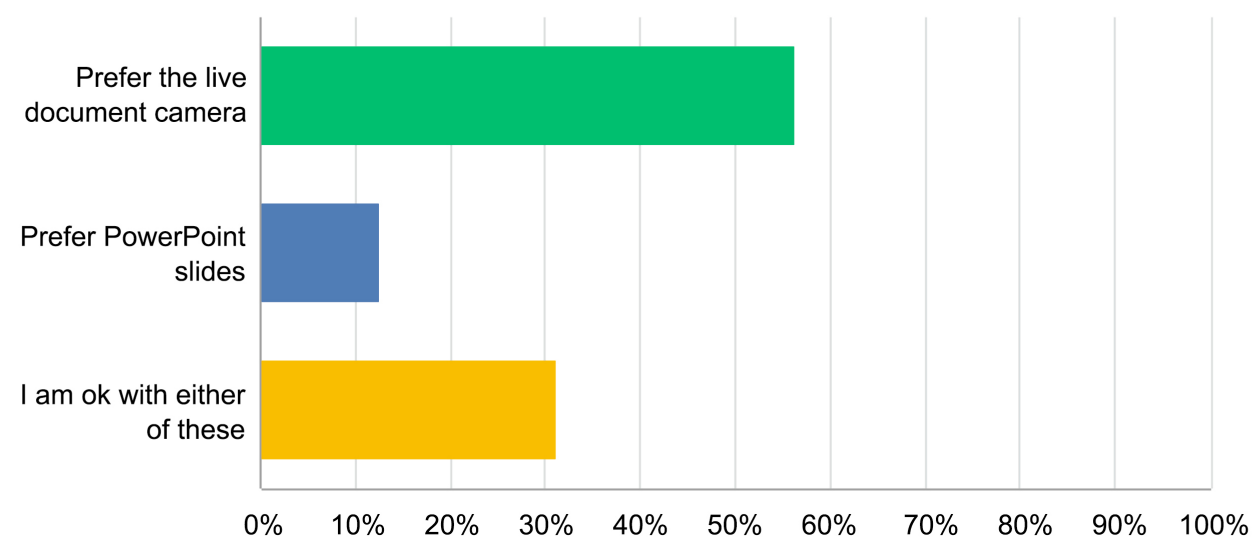

\section{ANSWER CHOICES}

- Prefer the live document camera

- Prefer PowerPoint slides

- I am ok with either of these TOTAL
- RESPONSES

$56.25 \%$

$12.50 \%$

$31.25 \%$ 5 16

Figure 9. Question 8 of the student survey. 
From Question 1, it is clear that for the majority of students $(81.25 \%)$ in the course, this course was not their first fully-online course. This is an important statistic as it paves the way for the other questions regarding online course experiences. From Question 2 it is clear that about one third of the class (or precisely $31.25 \%$ ) did not like the switch the University did for this course to a fully-online experience from the in-person experience. Despite that the majority of students were not experiencing their first fully-online course (Question 1) and that about a third of the class did not like the switch to an online format/modality, only one out of sixteen students did not like their virtual/online course experience (Question 3). Moreover, about two-thirds of the class thought that online course offering has advantages over in-person course offering (Question 4) keeping in mind that for the vast majority of students this was their first fully-online course. Nonetheless, most students did not think that virtual online course offering has more advantages than in-person offering (Question 5). However, most students said that they would consider taking another virtual/online course in the future, even if the COVID-19 pandemic no longer exists (Question 6).

One of the most important or telling questions is Question 7. In this question, the students are asked if the University did the right thing (given the pandemic of course) in moving the course to a fully-online format and eliminating the in-person meetings. A super majority of students, or 15 out of 16, agreed with that move. This is despite a third of them were not happy originally with the sudden shift to a pure online format (Question 2). This is an important statistics since a lot of universities, as mentioned in the Introduction, swiftly changed their in-person offering to primarily online offering of courses. It appears that most students are in agreement with the decisions of administrators at universities/colleges in moving away from in-person courses (at least for Fall 2020 semester/trimester).

The last question in the survey is specific to how course material was explained to the students. More specifically, it was in regard to the use of a document camera (see Figure 1) for this purpose versus the use of more traditional PowerPoint slides. From the answers to Question 8, only $12.5 \%$ had preference for PowerPoint slides. The author of this paper was predicting a majority of students, just like the respondents to this question, being content with the use of a document camera over PowerPoint slides since it mimicked more what students are used to in terms of writing on a whiteboard.

\subsection{Effect on Course Grades}

In addition to above, the course grades average and standard deviation for this Fall 2020 are compared to those from previous years when the same course was taught by the same instructor (Fall 2017-Fall 2019), see Table 1. As can be seen in such comparisons, there is no significant difference between the Fall 2020 grades and previous years (counting the one or two standard deviations in such comparison). This is despite that the grades have been trending down these last 
four years. More specifically, the grades from Fall 2020 (fully online course) and Fall 2019 (primarily in-person) are very close in their average number.

\subsection{Effect on Course Evaluations}

Finally, course evaluations at UNM ask the students to provide a rating from 1 5 on two inputs: 1) Please rate the instructor's overall teaching effectiveness, and 2) How comfortable do you feel approaching the instructor with questions or comments? As can be seen in Table 2, the course evaluations for Fall 2020 (fully online modality) are not worse than prior years (primarily in-person). Indeed, they seem to be better than prior years in general.

From the grade data and the course evaluation data, it appears that the move to a purely online course did not affect the student grade attainment nor did it adversely affect the course evaluations. In fact, the course evaluations seemed to improve. These results are similar to those obtained by other references (LaMeres \& Plumb, 2014; Reid, 2006; Pisupati \& Mathews, 2008; Douglas, 2015; Khraishi \& Denman, 2019). However, some of these references reported negative feelings from the students about their online course experience that was not seen in this paper here. However, this paper dealt with a graduate course whereas these references were concerned with undergraduate courses. The current results were also in line with those references teaching under COVID-19 conditions in late 2020 spring (George, 2020; Dost et al., 2020; Co \& Chu, 2020; Lee, 2020; Guo, 2020), in the sense that the online experience was taken well by most students, to varying extents, despite presenting some challenges for both teachers and students alike.

Table 1. Course grades for ME512 taught by the author.

\begin{tabular}{ccccc}
\hline Course Grades & Fall 2020 & Fall 2019 & Fall 2018 & Fall 2017 \\
\hline Average (out of 100) & 82.83 & 83.87 & 86.11 & 89.15 \\
Standard Deviation & 6.61 & 9.49 & 9.36 & 6.99 \\
\hline
\end{tabular}

Table 2. Course evaluations for ME512 taught by the author.

\begin{tabular}{ccc}
\hline $\begin{array}{c}\text { Course Evaluations } \\
(1-5 \text { rating with } \\
5 \text { being highest })\end{array}$ & $\begin{array}{c}\text { Please rate the instructor's } \\
\text { overall teaching } \\
\text { effectiveness: }\end{array}$ & $\begin{array}{c}\text { How comfortable do you } \\
\text { feel approaching the } \\
\text { instructor with questions } \\
\text { or comments? }\end{array}$ \\
\hline Fall 2020 (18 students) & 4.17 & 3.94 \\
Fall $2019(21)$ & 3.90 & 3.62 \\
Fall $2018(19)$ & 4.05 & 4.00 \\
Fall $2017(19)$ & 4.11 & 3.84
\end{tabular}




\section{Conclusion}

In conclusion, the author's overall experience teaching a fully online course that was live in nature, via Zoom was positive. This teaching modality was imposed by the COVID-19 crisis. Survey of the students showed that they supported the University's decision to move the in-person class to online in response to the pandemic. This is an important piece of data that helps validate the actions of many higher education institutions around the country in the era of the COVID-19 pandemic. Students also indicated that they are likely to take more live online courses in the future after this course taught by the author. Students further thought that online course offering offers some advantages over in-person course offering.

It was further concluded that the modality of the course offering (virtual and fully-online in Fall 2020) did not greatly impact the eventual course grades of the students comparing to past years (especially to last year of 2019). A similar conclusion was reached regarding the required University course evaluations done at the end of the semester. For the fully online course, the evaluations of both the course and teacher were better or on par with previous years when the class was offered then by the same teacher. It is concluded, based on the author's experience and collected data, that switching or transitioning traditional courses to virtual online courses can be successful, especially for graduate courses.

\section{Conflicts of Interest}

The author declares no conflicts of interest regarding the publication of this paper.

\section{References}

Arlington Public Schools (2020). What is the Difference between Synchronous and Asynchronous Instruction?

https://www.apsva.us/post/faq-difference-between-synchronous-and-asynchronous-ins truction/

Beek, M. V. (2011). Introduction: What Is "Virtual Learning"? https://www.mackinac.org/14475

Co, M., \& Chu, K. M. (2020). Distant Surgical Teaching during COVID-19-A Pilot Study on Final Year Medical Students. Surgical Practice, 24, 105-109. https://doi.org/10.1111/1744-1633.12436

Dost, S., Hossain, A., Shehab, M., Abdelwahed, A., \& Al-Nusair, L. (2020). Perceptions of Medical Students towards Online Teaching during the COVID-19 Pandemic: A National Cross-Sectional Survey of 2721 UK Medical Students. BMJ Open, 10, e042378. http://dx.doi.org/10.1136/bmjopen-2020-042378

Douglas, J. (2015). Comparing Learning Outcomes and Content Mastery in Online and Face-to-Face Engineering Statics Courses. Proceedings of the 122nd ASEE Annual Conference and Exposition, Seattle, 14-17 June 2015, Paper ID: 11840.

Drexel University School of Education (2020). The Benefits of Online Education in a Virtual Classroom.

https://drexel.edu/soe/resources/student-teaching/advice/benefits-of-online-and-virtua 
1-learning/

Finol, M. O. (2020). Asynchronous vs. Synchronous Learning: A Quick Overview. https://www.brynmawr.edu/blendedlearning/asynchronous-vs-synchronous-learningquick-overview

Gelles, L. A., Lord, S. M., Hoople, G. D., Chen, D. A., \& Mejia, J. A. (2020). Compassionate Flexibility and Self-Discipline: Student Adaptation to Emergency Remote Teaching in an Integrated Engineering Energy Course during COVID-19. Education Sciences, 10, 304. https://doi.org/10.3390/educsci10110304

George, M. L. (2020). Effective Teaching and Examination Strategies for Undergraduate Learning during COVID-19 School Restrictions. Journal of Educational Technology Systems, 49, 23-48. https://doi.org/10.1177\%2F0047239520934017

Guo, S. (2020). Synchronous versus Asynchronous Online Teaching of Physics during the COVID-19 Pandemic. Physics Education, 55, Article ID: 065007.

https://doi.org/10.1088/1361-6552/aba1c5

IGI Global (2020). What is Virtual Education? https://www.igi-global.com/dictionary/virtual-education/31665

Khraishi, T., \& Denman, K. (2019). Comparing Two Versions of An Engineering Course: In-Class and On-Line. What Does the Data Say? In T. Khraishi (Ed.), Proceedings of the 2018 Gulf Southwest Section Conference, Austin, TX: AT \& T Executive Education and Conference Center. https://peer.asee.org/31545

LaMeres, B. J., \& Plumb, C. (2014). Comparing Online to Face-to-Face Delivery of Undergraduate Digital Circuits Content. IEEE Transactions on Education, 57, 99-106. https://doi.org/10.1109/TE.2013.2277031

LearnCube (2017). Definition-What Is a Virtual Classroom? https://www.learncube.com/what-is-a-virtual-classroom.html

Lee, M. W. (2020). Online Teaching of Chemistry during the Period of COVID-19: Experience at a National University in Korea. Journal of Chemical Education, 97, 2834-2838. https://doi.org/10.1021/acs.jchemed.0c00881

Pisupati, S., \& Mathews, J. (2008). Differences in Teaching and Learning Outcomes in Face-to-Face, Online and Hybrid Modes of Energy Conservation Course. Proceedings of the ASEE Annual Conference and Exposition, Pittsburgh, 22-25 June 2008, 13.436.1-13.436.14.

Quintana, C. (2020). 'The Virus Beat Us': Colleges Are Increasingly Going Online for Fall 2020 Semester as COVID-19 Cases Rise.

https://www.usatoday.com/story/news/education/2020/07/29/covid-college-fall-semest er-2020-reopening-online/5530096002/

Reid, K. J. (2006). Study of the Success or Failure of Changing Freshman Engineering Technology Courses to an Online Format: Did it Work? Proceedings of the 36th ASEE/IEEE Frontiers in Education Conference, San Diego, 27-31 October 2006, 28-33. https://doi.org/10.1109/FIE.2006.322652

Ripoll, V., Godino-Ojer, M., \& Calzada, J. (2021). Teaching Chemical Engineering to Biotechnology students in the Time of COVID-19: Assessment of the Adaptation to Digitalization. Education for Chemical Engineers, 34, 94-105. https://doi.org/10.1016/j.ece.2020.11.005

The Chronicle of Higher Education (2020). Here's Our List of Colleges' Reopening Models. https://www.chronicle.com/article/heres-a-list-of-colleges-plans-for-reopening-in-the-f all/?bc nonce $=$ jyia98iucdh9a1omcajv2m\&cid=reg wall signup

Wikipedia (2020). Online Learning in Higher Education. https://en.wikipedia.org/wiki/Online learning in higher education 